\title{
El destinatario del enunciado modalizado deónticamente a partir del análisis de textos de derecho primario de la Unión Europea en español ${ }^{1}$
}

\section{Resumen:}

El presente artículo describe un aspecto del lenguaje jurídico español de la Unión Europea. La investigación está basada en un corpus de textos de derecho primario de la Unión Europea que incluye el Tratado de la Unión Europea, el Tratado de Funcionamiento de la Unión Europea y la Carta de Derechos Fundamentales de la Unión Europea. El artículo presenta el modo de realización del destinatario del enunciado modalizado deónticamente, destacando respectivamente el destinatario expresado de modo directo, el destinatario indirecto y el destinatario implicado.

Palabras clave: destinatario del enunciado normativo, modalidad deóntica, enunciado normativo, derecho primario de la Unión Europea

\footnotetext{
Abstract:

The Addressee of a Deontic-modified Sentence - the Case of Primary Law of the European Union in Spanish

The study describes one aspect of Spanish legal language of the European Union. The material studied consists of texts of the primary law of the European

1 El artículo está basado en un estudio realizado por la autora para la tesis doctoral "Modalność deontyczna w tekstach prawa pierwotnego Unii Europejskiej - na przykładzie tekstów w języku polskim i języku hiszpańskim”.
} 
Union, which include the Treaty on European Union, the Treaty on the Functioning of the European Union and the Charter of Fundamental Rights of the European Union. The study presents ways in which the addressee of a deontically-modified sentence is construed. Three specific types are distinguished: the addressee expressed directly, the indirect addressee and the implied addressee.

Keywords: addressee of the normative statement, deontic modality, normative statement, primary law of the European Union

\section{Introducción}

La problemática del lenguaje jurídico ya desde hace mucho tiempo despierta un gran interés tanto por parte de los lingüistas como de los juristas ${ }^{2}$. Dentro de esta problemática cabe destacar, sobre todo, las cuestiones relacionadas con el modo de expresar los derechos y las obligaciones de los destinatarios de la norma jurídica, esto es, su conducta adecuada. Con el fin de describir dicho fenómeno los autores adoptan, sobre todo, herramientas de ciencias tales como la teoría del derecho, la lógica y la lingüística.

El objetivo de este artículo es presentar las conclusiones acerca del modo de expresar el destinatario del enunciado normativo, entendido como una persona o institución indicada por el operador deóntico explícito o implícito ${ }^{3}$. Dichas conclusiones se sacaron mediante el análisis de los fenómenos lingüísticos observados en textos de derecho primario de la Unión Europea, que incluyen el Tratado de la Unión Europea (TUE), el Tratado de Funcionamiento de la Unión Europea

2 La problemática del lenguaje jurídico español la investigan, entre otros: Aguirre Beltrán y Hernando de Larramendi (1997), Alcaraz Varó y Hughez (2009), Borja Albi (2000), López Hernández (2005), y la del lenguaje jurídico polaco: Gizbert-Studnicki (1979), Malinowski (2006), Nowak-Michalska (2012), Pieńkos (1999).

3 Por el operador deóntico explícito se entiende cualquier medio léxico que sirve para expresar la modalidad deóntica; por el operador deóntico implícito se entiende cualquier otra forma de indicar el valor deóntico del enunciado, p.ej. el uso del futuro simple en español. 
(TFUE) y la Carta de Derechos Fundamentales de la Unión Europea (CDFUE).

Por la brevedad de la forma, en el artículo se presentarán las observaciones que describen solo un fragmento del problema investigado sin pretender dar una imagen exhaustiva de este.

\section{Algunas cuestiones teóricas}

Los textos de derecho primario de la Unión Europea, como todos los textos jurídicos, son portadores de normas jurídicas cuyo principal objetivo es determinar la conducta adecuada de sus destinatarios. La forma y función determinada de los textos jurídicos permite definirlos como textos de carácter convencional, en otras palabras, como textos que, por una parte, poseen una construcción estable y determinada y, por otra parte, funcionan en situaciones específicas (Woźniak, 2014: 442 y la literatura allá citada). Desde el punto de vista lingüístico, los determinantes de dicha convencionalidad son un vocabulario singular y unas tendencias sintácticas y estilísticas de carácter idiosincrático (Alcaraz Varó, 2009: 16 y la literatura allá citada).

Los textos jurídicos se componen de enunciados normativos, que afirman cómo uno debe o puede comportarse (Chauvin, Stawecki, Winczorek, 2009: 46; López Hernández, 2005: 470-472; Navarro, 2011: 1). Dichos enunciados, al igual que los enunciados del lenguaje natural, contienen dos elementos: el modus (realizado por un operador modal) y el dictum (Bally, 1965: 36).

Desde el punto de vista lingüístico, los enunciados normativos pueden, entonces, interpretarse como enunciados que contienen la modalidad deóntica, o sea, la modalidad que "se ocupa de la necesidad o posibilidad de los actos ejecutados por agentes moralmente responsables", según la descripción de esta modalidad propuesta por Lyons (1981: 754).

El autor observó también que los enunciados modalizados deónticamente "deben dirigirse necesariamente a otros agentes (por lo común, a otros seres humanos) cuya sumisión o no sumisión depende del ejercicio de su libre voluntad" (Lyons, 1981: 757). Desde el punto de 
vista jurisprudencial, los enunciados normativos se dirigen a los seres humanos (a las personas físicas) o a los establecimientos (p. ej. a los órganos e instituciones públicos o a las personas jurídicas) (Chauvin, Stawecki, Winczorek, 2009: 57-58). La información tanto sobre el destinatario como sobre las circunstancias en las que se le obliga, prohíbe o permite llevar a cabo alguna actividad se halla en la hipótesis de la norma jurídica. Esa, pues, especifica "los elementos subjetivos y objetivos de la situación que abarca" (Chauvin, Stawecki, Winczorek, 2009: 57-58) ${ }^{4}$.

Asimismo, se ha de prestar especial atención a la posibilidad de distinguir entre dos destinatarios del mismo enunciado normativo. Dicha posibilidad, prevista en la jurisprudencia, está relacionada con una construcción peculiar de la norma jurídica que, en caso de los así llamados permisos fuertes, establece la existencia de dos situaciones jurídicas: la básica y la derivada. La primera se entiende como la posibilidad de realizar un acto por parte del titular de derechos, mientras que la segunda tiene carácter de obligación, sobre todo, de respetar los actos del autorizado por parte del sujeto obligado jurídicamente (Chauvin, Stawecki, Winczorek, 2009: 66-67). Un permiso fuerte ejemplar puede tener aspecto de formalización $X$ tiene derecho a hacer algo que $Y$ está obligado a respetar o, incluso, $X$ tiene derecho a que $Y$ haga algo para $X$. Según la teoría del derecho, el destinatario de la situación jurídica básica es $X$ y el de la derivada, $Y$. En casos semejantes, en el presente trabajo se tomó en cuenta solo la situación jurídica básica.

4 Según la teoría del derecho, la norma jurídica se compone, generalmente, de dos elementos: de la hipótesis y de la disposición. La hipótesis de la norma jurídica identifica el destinatario de la norma y las circunstancias en las que se le ordena, prohíbe o permite hacer algo. La disposición de la norma jurídica determina el contenido de la conducta debida, es decir, muestra a su destinatario el comportamiento adecuado (Chauvin, Stawecki, Winczorek, 2009: 57-59). 


\section{El modo de expresar el destinatario del enunciado modalizado deónticamente en los textos de derecho primario de la Unión Europea}

El análisis del material investigado permitió distinguir los enunciados modalizados deónticamente que transmitían, respectivamente, el significado modal de la obligación, la prohibición, el permiso y la ausencia de obligación, según la teoría de Lyons (1981: 761-770). Dentro de cada grupo semántico se observaron los enunciados caracterizados por el destinatario tanto explícito como implícito. El análisis detallado de los fenómenos observados permitió clasificar formal y semánticamente los modos de expresar el destinatario de la estructura marcada deónticamente, teniendo en consideración el modo de su realización en el enunciado (realización explícita o implícita). La aplicación del último criterio nos llevó a la distinción entre el destinatario expresado de modo directo (destinatario expresado explícitamente) y el destinatario tanto indirecto como implicado (destinatario implícito).

\subsection{El destinatario expresado de modo directo}

El destinatario está expresado de forma directa cuando en el enunciado analizado se puede distinguir un elemento en función semántica de agente, es decir, de actante o de autor/ejecutor de la acción (Polański, 1999: 20). Esta condición se considera cumplida también en el caso de los enunciados en los que la ausencia del destinatario expresado de forma directa se debe a una construcción elíptica (que evita la repetición del término por causas estilísticas). En el caso de los textos de carácter jurídico, la función del destinatario la puede desempeñar no solo la persona física (el individuo), sino también la persona jurídica, el órgano o la institución.

Así definido, el destinatario lo encontramos en los enunciados que trasmiten los cuatro significados deónticos: la obligación, la prohibición, el permiso y la ausencia de obligación. Su existencia se observa en los enunciados que expresan la modalidad deóntica tanto de forma directa (con el operador deóntico explícito) como indirecta (con el operador deóntico implícito). 
En el material analizado, dentro de las estructuras que expresan el destinatario, se hallan, sobre todo, los lexemas clasificados morfológicamente como sustantivos y pronombres. En cuanto a las formas sustantivas, estas pueden ser simples, tener formas de SSNN complejos o, incluso, aparecer como elementos subordinados de tales sintagmas.

Las formas sustantivas simples aparecen en los enunciados que trasmiten el significado de la obligación, la prohibición y el permiso. Desde el punto de vista sintáctico, las formas sustantivas simples cumplen la función de sujeto de los enunciados con el operador deóntico explícito (la obligación y el permiso) y de los enunciados con el operador deóntico implícito (la obligación y la prohibición). Ejemplos de enunciados de ese tipo son los siguientes:

(1) [...] la Unión deberá reparar los daños causados [...] (art. 340 TFUE; la obligación).

(2) [... ] la Unión podrá celebrar acuerdos [...] (art. 8. 2. TUE; el permiso).

(3) $[\ldots]$ la Unión actúa dentro de los límites [...] (art. 5. 2. TUE; la obligación).

(4) La Unión no asumirá [...] los compromisos [...] (art. 125. 1. TFUE; la prohibición).

Los sustantivos simples en función sintáctica de complemento agente se observan solo en los enunciados con el operador deóntico implícito que trasmiten el significado de la obligación, p. ej.:

(5) Las normas [...] serán revisadas [...] por el Consejo [...] (art. 300. 5. TFUE; la obligación).

En cuanto al destinatario expresado por los SSNN compuestos, en el material analizado se observaron SSNN de varios tipos: con el modificador adjetival (ej. 8), con la aposición explicativa (ej. 10) o con el modificador en forma de sintagma preposicional (ej. 9).

Dentro de los grupos mencionados cabe destacar, también, los grupos nominales con los adjetivos indefinidos cada y ninguno, como p. ej.: 
(6) Cada Estado miembro facilitará al Consejo [...] un informe anual [...] (art. 148. 3. TFUE; la obligación).

(7) Ningún Estado miembro gravará $[\ldots]$ los productos $[\ldots]$ con tributos internos [...] (art. 110 TFUE; la prohibición).

Los grupos nominales con el adjetivo indefinido ninguno, por razones semánticas, aparecen solo en los enunciados que trasmiten el significado de la prohibición o la ausencia de obligación.

Los SSNN cumplen la función de sujeto del enunciado modalizado deónticamente en caso de los cuatro significados deónticos, p. ej.:

(8) El Comité Económico y Financiero emitirá un dictamen [...] (art. 126. 4. TFUE; la obligación).

(9) Los miembros del Tribunal de Cuentas no podrán [...] ejercer ninguna otra actividad [...] (art. 286. 4. TFUE; la prohibición).

(10) Todo Estado miembro podrá confiar a los interlocutores sociales [...] (art. 153. 3. TUE; el permiso).

(11) [...] los Estados miembros [...] no estarán obligados a contribuir a su financiación (art. 41. 2. TUE; la ausencia de obligación).

Los SSNN en función sintáctica de complemento agente se observan en los enunciados que trasmiten el significado de la obligación, la prohibición y el permiso, p. ej.:

(12) [...] la Comisión será nombrada por el Consejo Europeo [...] (art. 17. 7. TUE; la obligación).

(13) Queda prohibida [...] la adquisición [...] de instrumentos de deuda por el Banco Central Europeo o los bancos centrales nacionales (art. 123. 1. TFUE; la prohibición).

(14) [...] podrá ser cesado por el Tribunal de Justicia [...] (art. 247 TFUE; el permiso).

Los SSNN en función sintáctica de complemento preposicional del nombre se observan solo en los enunciados obligativos, p. ej.: 
(15) El Presidente, el Alto Representante [...] se someterán colegiadamente al voto de aprobación del Parlamento Europeo [... (art. 17. 7. TFUE; la obligación $)^{5}$.

En el material analizado se ha observado solo un ejemplo de realización pronominal del destinatario expresado directamente y como sujeto.

(16) Éstos [los Estados miembros] no impedirán que las apliquen [...] (art. 327 TFUE; la prohibición).

\subsection{El destinatario indirecto y el destinatario implicado}

La posibilidad de omitir el destinatario en un enunciado normativo fue advertida, entre otros, por Zieliński (2002: 104). El autor, en su teoría de la distribución de los elementos de la norma jurídica en determinadas disposiciones, observó que el contenido de la hipótesis de la norma jurídica podía no ser expresado en cada disposición y que era posible reconstruir su contenido en el proceso de la interpretación jurídica. En términos lingüísticos esto se traduce en la posibilidad de construir enunciados en los que no aparece el actante. Los enunciados de este tipo se pueden dividir en dos grupos distintos: los enunciados con el destinatario indirecto y los enunciados con el destinatario implicado.

En la terminología elaborada para este estudio, el destinatario es indirecto cuando en el enunciado analizado no se puede distinguir ningún elemento sintáctico o gramatical que se pueda analizar como correspondiente al agente. Los enunciados de este tipo adoptan la forma de enunciados en voz pasiva refleja, pasiva impersonal o pasiva perifrástica con el complemento agente omitido. Ejemplos de enunciados de ese tipo son los siguientes:

5 Aunque la construcción lingüística de la citada disposición pueda indicar lo contrario, de acuerdo con la interpretación jurídica de este artículo, no son el Presidente, el Alto representante [...] quienes tienen la obligación de someterse al voto del Parlamento Europeo, sino es el Parlamento Europeo quien está obligado a llevar a cabo la acción de votar. 
(17) Los derechos [...] se ejercerán en las condiciones [...] (art. 52. 2. CDFUE ; la obligación).

(18) [...] Se informará de esta solicitud al Parlamento Europeo [...] (art. 49 TUE; la obligación).

(19) Nadie podrá ser sometido a esclavitud [...] (art. 5. 1. CDFUE ; la prohibición).

En contra, el destinatario está implicado cuando en la posición del sujeto del enunciado modalizado deónticamente, en vez de la persona física (el individuo), la persona jurídica, el órgano o la institución, aparece, p. ej., nombre de un objeto.

Según el concepto adoptado por Wronkowska y Zieliński (2012: 37-38), los enunciados con el destinatario implicado destacan por la función particular del sujeto como "el elemento de la caracterización de la conducta obligada o permitida". Como ejemplo de ese tipo de enunciado los autores citaron el enunciado incompleto "la sentencia debe abarcar...", en el que el sustantivo la sentencia desempeñaba precisamente la función de sujeto. Dicho sustantivo, no puede, sin embargo, ser el destinatario del enunciado modalizado deónticamente que "se ocupa de la necesidad o posibilidad de los actos ejecutados por agentes moralmente responsables" (Lyons, 1981: 754). El destinatario real (el destinatario implicado) del enunciado citado arriba es entonces la persona encargada de redactar la sentencia de tal manera que comprenda un determinado contenido ${ }^{6}$. Es importante destacar también que el carácter deóntico del enunciado analizado lo determina, sobre todo, la presencia del operador deóntico explícito. En caso de dicho enunciado se trata del operador deóntico deber. Un ejemplo de enunciado de este tipo es, entre otros, el art. 256 apdo. 1 TFUE:

(20) [...] El Estatuto podrá establecer que el Tribunal General sea competente $[\ldots]$ (el permiso).

6 Esa cuestión la comentó también Nowak-Michalska (2012: 93) analizando el ejemplo del enunciado propuesto por Wronkowska y Zieliński (2012: 37-38) con el fin de describir el modo de construir el enunciado normativo desde el punto de vista de la jurisprudencia. 


\section{Conclusiones}

El análisis exhaustivo del material analizado ha permitido distinguir dos tipos fundamentales del modo de expresar el destinatario del enunciado normativo: el destinatario explícito y el destinatario implícito.

El destinatario expresado de forma directa (explícitamente) lo realizan generalmente sustantivos, pronombres o sintagmas nominales compuestos de palabras que pertenecen a las clases gramaticales recién mencionadas. Así formado, el destinatario aparece en los enunciados con el operador deóntico tanto explícito como implícito. La realización superficial del destinatario expresado de modo directo cumple la función sintáctica del sujeto, complemento agente o complemento preposicional del nombre.

En cuanto al destinatario implícito (no realizado en la superficie del enunciado), este se manifiesta de dos formas: como el destinatario indirecto o como el destinatario implicado. El primero es igualmente característico de los enunciados con el operador deóntico tanto explícito como implícito. El segundo se halla solo en los enunciados con el operador deóntico explícito. Cabe señalar que, a diferencia de los enunciados impersonales (pasiva impersonal y pasiva perifrástica) con el destinatario indirecto, los enunciados con el destinatario implicado se caracterizan por la presencia del sujeto en la superficie del enunciado. Dicho sujeto no cumple, sin embargo, con los requisitos establecidos para el destinatario del enunciado modalizado deónticamente, cuya función la pueden desempeñar solo un ser humano o un establecimiento.

Ambos tipos del destinatario implícito del enunciado modalizado deónticamente se reconstruyen en el proceso de la interpretación jurídica que, debido a su modo de realización, adopta la forma de una interpretación sistemática o funcional. Generalmente, los destinatarios implicados son los órganos y las instituciones públicas en sentido amplio.

El análisis del material empírico solo permitió observar ciertas tendencias en el modo de realización del destinatario del enunciado modalizado deónticamente. Fue imposible determinar si la ausencia de 
ciertas combinaciones del tipo de destinatario, del tipo de valor modal y del tipo de operador son consecuencias de alguna(s) pautas semánticas que las impiden o realizaciones de ciertas estrategias adoptadas para redactar los textos jurídicos estudiados.

\section{Bibliografía}

AGUIRRE BELTRÁN, B., HERNANDO DE LARRAMENDI, M. (1997), Lenguaje jurídico, SGEL, Madrid.

ALCARAZ VARÓ, E., HUGHES, B. (2009), El español jurídico, Ariel, Madrid.

BALLY, CH. (1965), Linguistique générale et linguistique française, Éditions Francke, Bern.

BORJA ALBI, A. (2000), El texto jurídico inglés y su traducción al español, Ariel Lenguas Modernas, Barcelona.

CHAUVIN, T., STAWECKI, T., WINCZOREK, P. (2009), Wstę do prawoznawstwa, C. H. Beck, Warszawa.

GIZBERT-STUDNICKI, T. (1979), „Czy istnieje język prawny”, Państwo i Prawo, 3, pp. 49-60.

LÓPEZ HERNÁNDEZ, J. (2005), “Clasificación de las normas jurídicas como enunciados de actos ilocutivos", Anuario de Derechos Humanos. Nueva Época, vol. 6, Madrid, pp. 455-509.

LYONS, J. (1981), Semántica, Teide, Barcelona.

MALINOWSKI, A. (2006), Polski język prawny. Wybrane zagadnienia, LexisNexis, Warszawa.

NAVARRO, P. E. (2011), "Permiso, enunciados normativos y proposiciones normativas", [on-line] https://e-archivo.uc3m.es/handle/10016/13857, 19.08.2020.

NOWAK-MICHALSKA, J. (2012), Modalność deontyczna w języku prawnym na przykładzie polskiego i hiszpańskiego kodeksu cywilnego, Wydawnictwo Rys, Poznań.

PIEŃKOS, J. (1999), Podstawy juryslingwistyki: język $w$ prawie, prawo w języku, Oficyna Prawnicza, Muza, Warszawa. 
POLAŃSKI, K. (1999), „Agens”, en: Polański K. (ed.), Encyklopedia językoznawstwa ogólnego, Wydawnictwo PAN Zakład Narodowy Imienia Ossolińskich, Wrocław-Warszawa-Kraków, p. 20.

WOŹNIAK, J. (2014), „Konwencjonalizacja w tekstach prawnych na przykładzie polskiej i niemieckiej wersji Traktatu Lizbońskiego", en: Łukasik, M., Mikołajewska, B. (eds.), Języki specjalistyczne wczoraj, dziś i jutro, Wydawnictwo Naukowe Instytutu Kulturologii i Lingwistyki Antropocentrycznej UW, Warszawa, pp. 440-453.

WRONKOWSKA, S., ZIELIŃSKI, M. (2012), Komentarz do zasad techniki prawodawczej z dnia 20 czerwca 2002 r., Wydawnictwo Sejmowe, Warszawa.

ZIELIŃSKI, M. (2002), Wykładnia prawa. Zasady-reguły-wskazówki, LexisNexis, Warszawa. 